\title{
Otolog Hematopoetik Kök Hücre Nakli Yapılan Hastalarda Komorbidite İndekslerinin Sağkalım ile İlişkisinin Değerlendirilmesi
}

\author{
Evaluation of the Relationship Between Comorbidity Indexes and Survival in Autologous Hematopoietic Stem Cell
}

Transplant Patients

${ }^{1}$ Eskișehir Osmangazi Üniversitesi Tip Fakültesi Hematoloji Bilim Dalı Eskişehir, Türkiye

${ }^{2}$ Uludağ Üniversitesi Tip Fakültesi Hematoloji Bilim Dalı Bursa, Türkiye

${ }^{3}$ Bursa Kestel Devlet Hastanesi İç Hastalıkları Bursa, Türkiye

\section{${ }^{1}$ Fatih Yaman, ${ }^{2}$ Vildan Özkocaman, ${ }^{2}$ Fahir Özkalemkaş, ${ }^{3}$ Sedat Çelikçi}

\section{Özet}

Bu çalışmanın amacı hematopoetik kök hücre nakli yapılan hastalarda komorbidite indekslerinin sağkalımı öngörmede prediktif değerlerini saptamaktı. Ağustos 2009-Mart 2014 tarihleri arasında otolog hematopoetik kök hücre nakli (OHKHN) yapılan hematolojik maligniteli 110 hastanın verileri retrospektif olarak incelendi. Komorbidite indeksleri ve sağkalım süreleri arasındaki ilişki Kaplan-Meier testi kullanılarak incelendi. OHKHN yapılan 110 hastanın 58'ini (\%53) kadın, 52'sini (\%47) erkek hastalar olușturmaktaydı. Hastaların ortanca yașı 54 (22-72)'tü. OHKHN yapılan hastaların 84'ü (\%76) Multipl miyelom (MM), 18'i (\%17) Non-hodgkin lenfoma (NHL), 8'i (\%7) Hodgkin lenfoma (HL) tanılıdı. 2 yıllık takiplerinde hastaların 57’si (\%52) nüks olmuştu, 53’ü (\%48) remisyondaydı, 40’1 (\%36) hayatını kaybetmişti. Hayatta olan 70 (\%64) hasta vardı. En sık komorbiditeler pulmoner hastalıklar (\%33), psikiyatrik hastalıklar (\%29) ve enfeksiyon hastalıklarıdıd (\%20). Hematopoietic Cell Transplantation Comorbidity Index (HCT-CI), Flexible Hematopoietic Cell Transplantation Comorbidity Index (Flexible HCT-CI) ve Charlson Comorbidity Index (CCI) skoru ile progresyonsuz sağkalım ve genel sağkalım arasındaki ilişki incelendiğinde istatistiksel anlaml bir ilişki bulunamadı ( $p>0.05)$. Yapılan çalıșmalarda genel sağkalımı en iyi öngören komorbidite skoru HCT-CI olmakla birlikte bizim çalışmamızda daha sık 65 yaş altı, perfomans durumu iyi olan, komorbid hastalığı az olan hastalara nakil yapılması nedeni ile HCT-CI komorbidite skorunun bu grup hastalarda kullanımı ve sağkalımı öngörmedeki etkisi kısıtlıdır. Komorbidite indekslerindeki parametre sayıları arttıkça sağkalımı öngörmedeki duyarlılıkları artmaktadır. Nakil öncesi rutin kullanıma girmeleriyle birlikte bu konuyla ilgili tecrübelerimiz artacaktır.

Anahtar Kelimeler: hematopoetik kök hücre nakli, komorbidite indeksleri, genel sağkalım, progresyonsuz sağkalım

\section{Abstract}

The aim of this study was to determine the predictive value of comorbidity indexes for survival in hematopoietic stem cell transplant patients. Data of 110 hematologic malignant patients who underwent autologous hematopoietic stem cell transplantation (OHKHN) between August 2009 and March 2014 were retrospectively reviewed. Comorbidity indexes and survival times were analyzed using the associated Kaplan-Meier test. Of the 110 patients who underwent OHKHN, 58 (53\%) were female and $52(47 \%)$ were male patients. The median age of the patients was 54 years. Multiple myeloma (MM), 18 (17\%) Non-hodgkin's lymphoma (NHL) and $8(7 \%)$ Hodgkin's lymphoma (HL) were found in 84 patients (76\%). In 2 years follow-up of 110 patients with autologous transplantation, $57(52 \%)$ had recurrences. 53 patients $(48 \%)$ were in remission. Patients had lost $40(36 \%)$ of their lives for 2 years. There were 70 (64\%) patients in life. There was no statistically significant relationship between the Hematopoietic Cell Transplantation Comorbidity Index (HCT-CI), Flexible Hematopoietic Cell Transplantation Comorbidity Index (Flexible HCT-CI) and Charlson Comorbidity Index (CCI) scores and disease free survival and total survival ( $p>0.05)$. Although HCT-CI is the best predictor of overall survival in studies, the use of the HCT-CI comorbidity score in this group of patients and its effect in predicting survival is limited in our study because of transplantation to patients under 65 years of age, with good performance and low comorbid disease. As the number of parameters in the comorbidity indices increases, their sensitivity in predicting survival increases. Our experience on this subject will increase as they enter into routine use before transplantation.

Keywords: hematopoietic stem cell transplantation, comorbidity indexes, overall survival, progression free survival 


\section{Giriş}

Hematopoetik kök hücre nakli (HKHN) lösemi, lenfoma, multipl miyelom gibi malign hematolojik hastalıkların yanında aplastik anemi, bazı solid tümörler, gibi birçok hastalığın tedavisinde kullanılmaktadır (1). HKHN ile önemli bir oranda hastalık kontrolü ve kür sağlama başarısı yakalanmıştır. Hematopoetik kök hücre (HKH); kemik iliğinde, bebek kordon kanında, periferik kanda bulunan kan hücrelerine dönüşebilen kök hücreleridir (2). HKHN kemik iliği veya periferik kandan HKH'lerin toplanması ve hastaya infüzyon yolu ile verilmesi işlemidir. Otolog HKHN (OHKHN) ise hastanın kendi hücrelerinin infüzyonla kendine verilmesi işlemidir $(3,4)$.

HKHN birçok ciddi hastalık için kür şansı sağlayan tek tedavi yöntemi olmasına karşın önemli oranda mortalite ve morbiditeyi de beraberinde taşımaktadır. Hastalık evresi, yaşı, HLA uyumu, alıcı ve verici arasındaki cinsiyet uyumu, komorbid hastalıklar nakil ilişkili komplikasyon ve mortaliteyi belirlemektedir (5).

Yapılan çalışmalarda hastaların komorbid

gösterilmiştir (6). Hastalara HKHN yapılmadan önce risk durumlarını belirlemek için çeşitli komorbidite indekslerinden yararlanılmıştır. Nakil öncesi komorbid hastalıklarının ciddiyeti ve laboratuvar değerlerine göre her komorbidite indeksi için farkl1 parametreler ve farklı skorlama sistemleri geliştirilmiştir. Hematopoietic Cell Transplantation Comorbidity Index (HCT-CI), Flexible Hemotopoietic Cell Transplantation Comorbidity Index (Flexible HCT-CI), Charlson Comorbidity Index (CCI) bu komorbidite indekslerinden en sik kullanılanlarıdır (7-10).

Yapılan çalışmalarda yaş arttıkça komorbiditelerin yükünü $\quad \operatorname{artırdığ~} 1$ gösterilmiştir. $\mathrm{Bu}$ nedenle $\mathrm{HCT}-\mathrm{CI}$ revize edilerek hasta yaşı eklenmiştir. Flexible HCTCI hesaplanırken yaş> 40 olan hastalara 1 puan ilave edilir (9). Retrospektif olarak yapılan bu çalışmada hesaplanan komorbidite indekslerini karşılaştırılarak 2 yıllık progresyonsuz sağkalım ve genel sağkalımı öngörmede prediktif değerlerini saptamayı amaçladık. hastalıklarının sağkalım süresini azalttı̆g 1

Tablo 1. Charlson Komorbidite İndeksi Skorlama Sistemi (11)

\begin{tabular}{|c|c|}
\hline SKOR & DURUM \\
\hline \multirow[t]{9}{*}{1} & $\begin{array}{l}\text { Miyokard infarktüsü (geçirilmiş, sadece EKG değişiklikleri hariç) } \\
\text { Konjestif kalp yetmezliği }\end{array}$ \\
\hline & Periferik vasküler hastalık ( $\geq 6 \mathrm{~cm}$ aort anevrizması dahil) \\
\hline & Serebrovasküler hastalık (SVO, TIA) \\
\hline & Demans \\
\hline & Kronik akciğer hastalığı \\
\hline & Bağ doku hastalığı \\
\hline & Peptik ülser \\
\hline & Hafif karaciğer hastalığı (kronik hepatitler dahil) \\
\hline & Diyabet organ komplikasyonsuz (sadece diyetle kontrol edilenler hariç) \\
\hline \multirow[t]{6}{*}{2} & Hemipleji \\
\hline & Orta veya ağır böbrek hastalığı \\
\hline & Diyabet organ komplikasyonu ile birlikte \\
\hline & Tümör metastatik olmayan (tanıdan itibaren 5 yıl geçmişse dahil edilmez) \\
\hline & Lösemi (akut veya kronik) \\
\hline & Lenfoma \\
\hline 3 & Orta veya ağır karaciğer hastalığı \\
\hline \multirow[t]{2}{*}{6} & Metastatik solid tümör \\
\hline & AIDS (sadece HIV pozitif hastalara puan verilmez) \\
\hline
\end{tabular}

EKG: Elektrokardiyografi, SVO: Serebrovasküler Olay, TIA: Transiskemik Atak, AIDS: Edinsel İmmun Yetmezlik Sendromu, HIV: Human Immundeficiency Virus 
Tablo 2. Hematopoietic Cell Transplantation- Komorbidite İndeksi (7)

\begin{tabular}{|c|c|c|}
\hline Komorbiditeler & Tanımlar & Skor \\
\hline \multirow[t]{2}{*}{ Aritmi } & Atriyal fibrilasyon, Atriyal flutter & 1 \\
\hline & Hasta sinüs sendromu, Ventriküler aritmi & \\
\hline \multirow[t]{2}{*}{ Kardiyovasküler } & Koroner arter hastalığı, Miyokard enfarktüsü & 1 \\
\hline & Konjestif kalp yetmezliği, $\mathrm{EF} \leq 50$ & \\
\hline İnfalamatuar Barsak Hastalığı & Crohn hastalığ 1 , Ülseratif kolit & 1 \\
\hline Diyabet & OAD veya insülin kullanan hastalar & 1 \\
\hline Serebrovasküler Hastalıklar & TIA, Serebral emboli, tromboz, hemoraji, SAK & 1 \\
\hline Psikiyatrik hastalıklar & Depresyon, anksiyete tedavi alanlar & 1 \\
\hline \multirow{2}{*}{ Karaciğer hastalığı - orta } & Kronik hepatit & 1 \\
\hline & bilirubin $\geq \mathrm{NÜS}-1,5 * \mathrm{NÜS}, \mathrm{AST} / \mathrm{ALT} \geq \mathrm{NÜS}-2,5 * \mathrm{NÜS}$ & \\
\hline \multirow[t]{2}{*}{ Obezite } & $\mathrm{BMI} \geq 35$ erişkinlerde & 1 \\
\hline & Yaşa göre BMI $\geq 95$. Percantil (çocuklarda) & \\
\hline \multirow[t]{3}{*}{ Enfeksiyon } & Dokümente enfeksiyon, Nedeni bilinmeyen ateş & 1 \\
\hline & Fungal pnömoni şüpheli pulmoner nodüller & \\
\hline & Tbc profilaksisi gerektiren PPD pozitifliği & \\
\hline Romatolojik hastalıklar & SLE, RA, Polimyozit, MKDH, Polimiyalji romatika & 2 \\
\hline \multirow[t]{2}{*}{ Peptik ülser } & Gastik ülser, duodenal ülser & 2 \\
\hline & Endoskopiyle doğrulanmış ve Tedavi gerektiren & \\
\hline \multirow[t]{2}{*}{ Böbrek hastalıkları -orta/ağır } & Serum Kreatin $>2 \mathrm{mg} / \mathrm{dl}$ & 2 \\
\hline & Diyaliz alan, Böbrek nakli yapılmış & \\
\hline \multirow[t]{2}{*}{ Akciğer hastalıkları -orta } & DLCO ve/veya FEV1 $\% 66-\% 80$ arasında & 2 \\
\hline & Dispne hafif aktiviteyle & \\
\hline \multirow[t]{2}{*}{ Akciğer hastalıkları -ağır } & DLCO ve/veya FEV $1 \leq \% 65$ & 3 \\
\hline & Dispne istirahatte, Oksijen tedavisi alan & \\
\hline Kalp kapak hastalıkları & Asemptomatik MVP hariç & 3 \\
\hline \multirow[t]{2}{*}{ Solid maligniteler } & Tedavi almış olan & 3 \\
\hline & Non- melanom cilt kanserleri hariç & \\
\hline \multirow[t]{2}{*}{ Karaciğer hastalıkları orta/ağır } & Siroz & 3 \\
\hline & Bilirubin $>1,5 *$ NÜS, AST/ALT>2,5*NÜS & \\
\hline
\end{tabular}

\section{Gereç ve Yöntemler}

Uludağ Üniversitesi İç Hastalıkları Anabilim Dalı, Hematoloji Bilim Dalı, Kemik İliği Nakil Ünitesinde Ağustos 2009-Mart 2014 tarihleri arasında otolog hematopoetik kök hücre nakli yapılan hematolojik maligniteli 110 hastanın verileri retrospektif olarak incelendi. Hasta verileri "International Classification of Disease (ICD)" tanı kodları ile medikal kayıtlarımızdan elde edildi. Uludağ Üniversitersi Tıp Fakültesi Girişimsel Olmayan Klinik Çalışmalar Etik Kurulundan 15.03.2016 tarihinde 2016-4/6 say1 numaras1 ile etik kurul onayı alınd.

\section{İstatiksel Analiz}

Verilerin istatistik analizi için SPSS versiyon 21.0 yazılımı kullanıldı. Değişkenlerin normal dağılım gösterip göstermediğini değerlendirmek için Kolmogorov-Smirnov testi kullanıldı. Kategorik veriler sıklık ve yüzde (\%) olarak verildi. Normal dağılım göstermeyen değişkenler median (minimummaksimum) olarak ifade edildi. OHKHN yapilan hastalarda HCT-CI, Flexible HCT-CI, CCI indeksleri hesapland. Hesaplanan komorbidite skorları HCT-CI için düşük (0), orta (1-2), yüksek (>2); Flexible HCT-CI için düşük (0-3), orta (4-5), yüksek (>5); CCI için düşük (0), orta (1-2), yüksek $(>2)$ risk olmak üzere 3 gruba ayrıldı. Komorbidite indeksleri ve sağkalım süreleri arasındaki ilişkili Kaplan-Meier testi kullanılarak incelendi. Hesaplanan her komorbidite indeksinin 2 yıllık progresyonsuz sağkalım ve genel sağkalım ile ilişkisi incelendi. Anlamlılık düzeyi $p<0.05$ olarak belirlenmiştir. 


\section{Bulgular}

OHKHN yapılan 110 hastanın 52'sini (\%47) erkek hastalar oluşturmaktaydi. Hastaların ortanca yaşı 54'tü (22-72). Hastaların demografik özellikleri tablo 3 'te verilmiştir.
Hastalar tanılarına göre gruplandığında OHKHN yapilan en sik hasta grubu \%76 $(\mathrm{n}=84)$ ile multipl miyelom (MM)'du. OHKHN yapılan diğer hastalıklar ve alt tipleri Tablo-4'de verilmiştir.

Tablo 3. OHKHN yapılan hastaların özellikleri

\begin{tabular}{clll}
\hline & $\mathbf{n = 1 1 0}$ & $\mathbf{( \% )}$ \\
\hline $\begin{array}{c}\text { Ortanca yaş } \\
\text { Cinsiyet }\end{array}$ & $54(22-72)$ & \\
$\bullet \quad$ Kadın & 58 & $(53)$ \\
\hline$\quad$ Erkek & 52 & $(47)$ \\
\hline Tanı & & \\
$\bullet \quad$ MM & 84 & $(76)$ \\
$\bullet \quad$ NHL & 18 & $(17)$ \\
$\bullet \quad$ HL & 8 & $(7)$ \\
\hline
\end{tabular}

MM: Multipl Miyelom, NHL: Non Hodgkin Lenfoma, HL: Hodgkin Lenfoma OHKHN: Otolog Hematopoetik Kök Hücre Nakli

Tablo 4. Hastalık tanılarının alt tiplere göre dağılımı

\begin{tabular}{|c|c|c|}
\hline МM & & $(\% 76)$ \\
\hline$\bullet$ & IgG kappa/lambda & $46(\% 41,8)$ \\
\hline$\bullet$ & lgA kappa/lambda & $15(\% 13,6)$ \\
\hline - & Kappa hafif zincir & $12(\% 10,9)$ \\
\hline • & Lambda hafif zincir & $8(\% 7,3)$ \\
\hline - & IgD hafif zincir & $1(\% 0,9)$ \\
\hline$\bullet$ & Nonsekretuar & $1(\% 0,9)$ \\
\hline - & Plazmositom & $1(\% 0,9)$ \\
\hline NHL & & $(\% 17)$ \\
\hline - & DBBHL & $10(\% 9)$ \\
\hline • & Mantle cell lenfoma & $4(\% 3,6)$ \\
\hline • & Büyük hücreli anaplastik lenfoma & $3(\% 2,7)$ \\
\hline • & Periferal T hücreli lenfoma & $1(\% 0,9)$ \\
\hline HL & & $(\% 7)$ \\
\hline$\bullet$ & Klasik tip & $4(\% 3,6)$ \\
\hline - & Nodüler sklerozan & $4(\% 3,6)$ \\
\hline
\end{tabular}

MM: Multipl Miyelom, NHL: Non Hodgkin Lenfoma, HL: Hodgkin Lenfoma DBBHL: Diffüz Büyük B Hücreli Lenfoma, Ig: Immunglobulin 
MM tanılı 84 hastanın 4'ü (\%5) International Staging System (ISS)'ye göre evre 1, 30'u (\%35) evre 2, 50'si (\%60) evre 3 'tü. Lenfoma tan1l hastalarda ise Ann-Arbor Evrelendirme Sistemine göre evre 1 olan 1 hasta (\%3); evre 2, 7 hasta (\%26); evre 3, 10 hasta (\%38); evre 4,8 hasta $(\% 30)$ vard.

MM hastalarında $200 \mathrm{mg} / \mathrm{m} 2$ melfelan kullanıld1. Lenfoma tanilı hastalara ise busulfan $3.2 \mathrm{mg} / \mathrm{kgx} 4$ gün ve siklofosfamid $60 \mathrm{mg} / \mathrm{kgx} 2$ gün verildi. MM tanılı 4 hasta kronik böbrek yetmezliği nedeniyle hemodiyaliz tedavisi alıyordu. $\mathrm{Bu}$ hastalara melfelan $140 \mathrm{mg} / \mathrm{m} 2$ verildi. Hemodiyaliz alan hastalarda ek hastalıklar nedeniyle komorbidite skorlar1 yüksekti (CCI:5-6, HCTCI:5-8, F-HCT-CI:6-9). Hepatik komorbiditesi olan hastaların 7'si HBV, 1'i HCV tanıliydi. 11 hastada hafif derecede AST/ALT yüksekliği mevcuttu. Bu hastalarda hazırlık rejimlerinde doz modifikasyonu yapilmadi.

OHKHN yapılan hastaların 37'sinde (\%33) hastada pulmoner komorbidite, 32 (\%29) hastada psikiyatrik hastalık, 23 (\%20) hastada enfeksiyon hastalıkları, 19 (\%17) hastada hepatik komorbidite, $16 \quad(\% 14)$ hastada diyabet mellitus (DM), 13'ünde (\%11) kardiyak hastalık, $6(\% 5)$ hastada renal komorbidite, $6(\% 5)$ hastada gastrointestinal hastalık, $6(\% 5)$ hastada periferik vasküler hastalık, $6(\% 5)$ hastada obezite, 4 (\%3) hastada serebrovasküler hastalık, $1 \quad(\% 0,9)$ hastada romatolojik hastalık mevcuttu. İnflamatuar barsak hastalığı ve malignite tanılı hasta yoktu.

Otolog nakil yapılan 110 hastanın 2 y1llı takiplerinde 57'si (\%52) nüks olmuştu. Hastaların 53'ü $(\% 48)$ remisyondaydı. Hastaların 2 yıllık takipte 40 '1 (\%36) hayatını kaybetmişti. Hayatta olan 70 (\%64) hasta vard1.
HCT-CI skoru düşük olan 18 hasta vardı. Takiplerinde 2 yılda $10(\% 55)$ hastada nüks gelişmişti. Remisyonda olan $8(\% 45)$ hasta vardı. Hastaların 6's1 (\%33) 2 yıllık takipte hayatını kaybetmişti. Orta riskli olan 57 hastanın 34'ünde (\%59) nüks gelişmişti. Remisyonda olan $23(\% 41)$ hasta, ölen 21 (\%36) hasta vardı. Yüksek riskli olan 35 hastanın 13'ü (\%37) nüks olmuştu. Remisyonda 22 (\%63) hasta ve ölen 13 (\%37) hasta mevcuttu. HCT-CI skoru ile progresyonsuz sağkalım ve genel sağkalım arasındaki ilişki incelendiğinde istatistiksel anlamlı bir ilişki bulunmadı. ( $\mathrm{p}=0.068$ ve $\mathrm{p}=0.897$ )

Flexible HCT-CI skoru düşük olan 77 hasta vardi. Hastaların 45'inde (\%58) nüks gelişmişti. Remisyonda $32(\% 42)$ hasta ve ölen 28 (\%36) hasta vard1. Orta riskli 22 hastanın 10'unda (\%45) nüks olmuştu. Remisyonda 12 hasta (\%55) ve ölen $5(\% 22)$ hasta vardı. Yüksek riskli 11 hastanın 2'sinde (\%18) nüks olmuştu. Remisyonda 9 (\%82) hasta, ölen 7 (\%63) hasta mevcuttu. Flexible HCT-CI skoru ile progresyonsuz sağkalım ve genel sağkalım arasında istatistiksel anlamlı bir ilişki saptanmadı $(\mathrm{p}=0.085$ ve $\mathrm{p}=0.071)$.

CCI skoru düşük olan 23 hastanın 15'i (\%65) nüks olmuştu. Remisyonda 8 (\%34) hasta ve ölen $8(\% 34)$ hasta mevcuttu. Orta riskli olan 57 hastanın 30'u (\%52) nüks olmuştu. Remisyonda 27 (\%48) hasta ve ölen 20 (\%35) hasta vardı. Yüksek riskli 30 hastanın 12 'sinde (\%40) nüks olmuștu. Remisyonda 18 $(\% 60)$ hasta ve ölen $12(\% 40)$ hasta vard1. CCI skoru ile progresyonsuz sağkalım ve genel sağkalım arasında istatistiksel anlamlı bir ilişki saptanmadı $(\mathrm{p}=0.279$ ve $\mathrm{p}=0.705)$. Komorbidite indeksleri ile genel sağkalım ve progresyonsuz sağkalım arasındaki ilişki Tablo-5'de özetlenmiştir. 
Tablo 5. OHKHN yapılan hastalarda komorbidite indeksleri ile sağkalım arasındaki ilişkinin değerlendirilmesi.

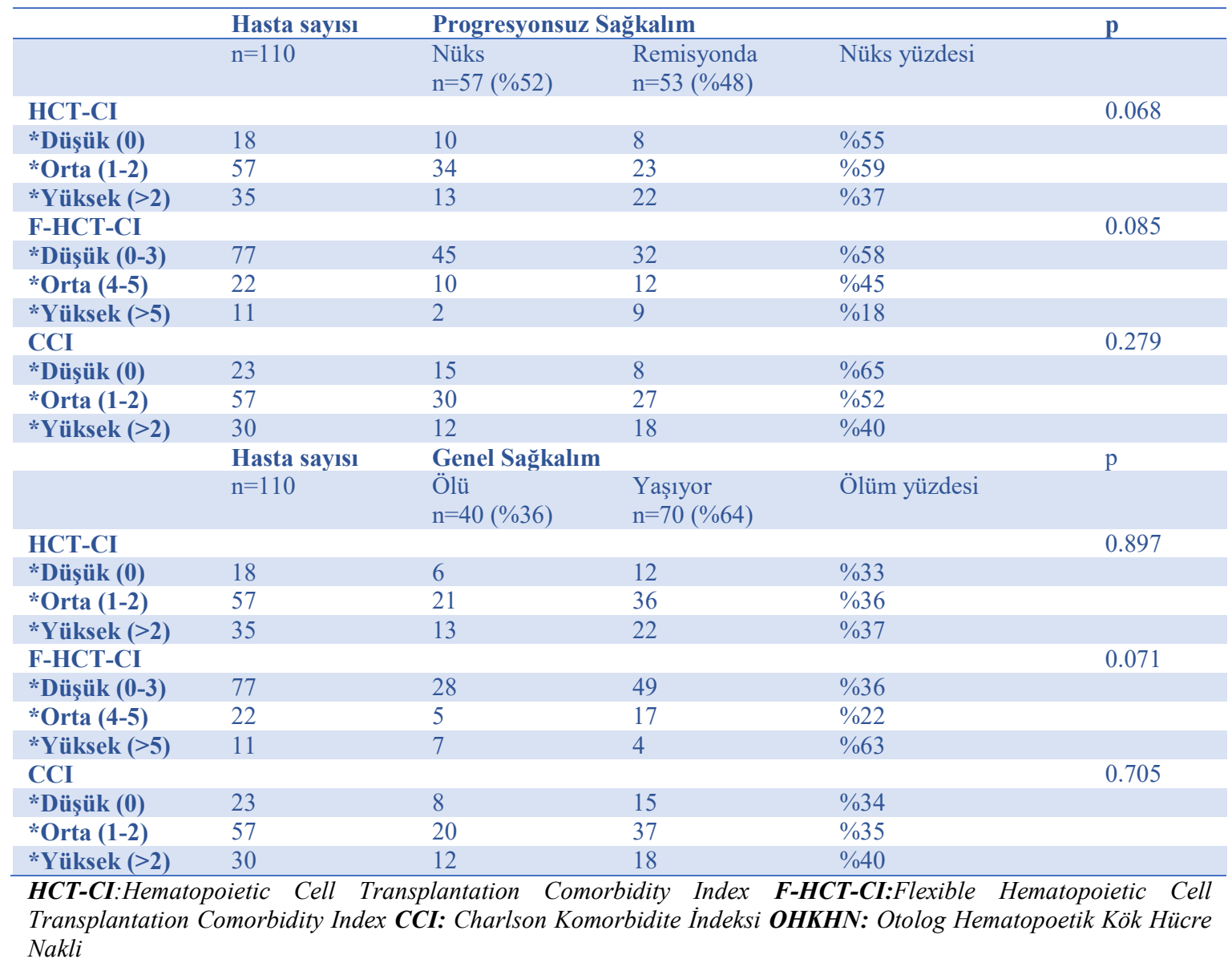

\section{Tartışma ve Sonuç}

HKHN hematolojik maligniteli hastaların tedavisinde gün geçtikçe daha yaygın halde kullanılmaya başlanmıştır. Artan nakil sayısı ve 65 yaş üstü hastalara da nakil yapılmaya başlanmasıyla birlikte hastaların komorbid hastalıkları önemli bir sorun haline gelmiştir. Nakil hastalarında eşlik eden komorbid hastalıklar mortalite ve morbiditede artışa neden olmaktadır (12-14). Komorbid hastalıkların morbidite ve mortalite üzerine etkisini öngörmek üzere çeşitli komorbidite indeksleri geliştirilmiştir. Literatürde bu komorbidite indeksleriyle ilgili yapılmış az sayıda çalışma vardır (15-17). Yaptığımız bu tek merkezli çalışmamızda OHKHN yapılan hematolojik maligniteli hastalarda komorbidite indekslerinin progresyonsuz sağkalım ve genel sağkalım üzerine etkisini belirlemeye çalıştık.
OHKHN yapılan 110 hastanın median yaşı, cinsiyeti, hastalık tanılarının dağılımı literatür ile uyumluydu. Bizim çalışmamızda OHKHN yapılan 110 hastadan nüks olan 57 (\%52) ve ölen 40 (\%36) hasta mevcuttu. OHKHN yapılan hastaların 84'ü (\%76) Multipl miyelom (MM), 18'i (\%17) Non-hodgkin lenfoma (NHL), 8'i (\%7) Hodgkin lenfoma (HL) tanıliydı. En sık görülen komorbiditeler pulmoner hastalıklar, psikiyatrik hastalıklar, enfeksiyon, hepatik komorbiditeler, diyabet ve kardiyak komorbiditelerdi.

M Kleber ve arkadaşlarının 2011 yılında yayınladığı bir çalışmada $127 \mathrm{MM}$ tanılı hasta incelenmiş HCT-CI genel sağkalım ile ilişkili bulunurken CCI skoru mortalite ile ilişskili saptanmamış (18). Ayman Saad ve arkadaşları tarafindan 2014 yilında yapilan 1156 MM tanılı OHKHN yapılan hastanın dâhil edildiği 
çok merkezli bir çalışmada ise HCT-CI skorunun mortaliteyle ilişkisi incelenmiștir. HCT-CI skoru $0,1,2,3$ ve $>3$ olan $\% 42$, $\% 18, \quad \% 13, \% 13$ ve $\% 14$ hasta olduğu saptanmıştır. En sık görülen komorbiditelerin pulmoner, diyabet, obezite, psikiyatrik, kardiak ve renal komorbiditeler olduğu bulunmuştur. Yüksek HCT-CI skorları relaps dışı mortalite ile ilişkili bulunmamış, fakat genel sağkalımı azalttığ görülmüştür. Hasta yaşının relaps dışı mortalite ve genel sağkalım üzerine ilişkisi gösterilememiştir (19). Bizim çalışmamızda her üç komorbidite indeksi de (HCT-CI, Flexible HCT-CI, CCI) progresyonsuz sağkalım ve mortalite ile ilişkili bulunamadı. Çalışmamızda anlamlı ilişki bulunamamasının sebebi 65 yaş altı, perfomans durumu iyi olan, komorbid hastalığ 1 az olan hastalara nakil yapılması; yaşlı ve komorbiditesi fazla olan hastalarda naklin tercih edilmemesi; çalışmaya dahil edilen hasta sayısının az olması, farklı tanıları olan heterojen bir hasta grubunun olmasi olabilir.

Komorbidite indeksleriyle yapılan çalışmalarda farklı sonuçlar elde edilmiștir. $\mathrm{Bu}$ sonuçlara göre genel sağkalımı en iyi öngören komorbidite skoru HCT-CI olarak gözükmektedir. HCT-CI skoru ile sağkalım arasında ilişki kurulamayan çalışmalarda farklı tanılara sahip hasta gruplarının bir arada değerlendirilmesinin buna neden olduğu düşünülmüștür. EKO, SFT ve DLCO parametrelerinin eklenmesiyle pulmoner ve kardiyak komorbiditeler daha objektif olarak değerlendirilmiştir $(6,7)$. Bizim çalışmamızda ve mevcut çalışmaların hepsinde en sık saptanan komorbid hastalik pulmoner hastalıklardır. SFT ve DLCO testlerinin parametrelere eklenmesi HCT-CI skorunun duyarlılığını artırmış, HCT-CI skorunu diğer diğer komorbidite indekslerine göre daha ön plana geçirmiştir.

Komorbidite indeksleri s1klıkla AHKHN yapılan hastalarda kullanılmaktadır. Her ne kadar OHKHN sirasinda uzun dönemde progresyonsuz sağkalımı predikte ettikleri bazı çalışmalarda gösterilse de kısa dönemde etkinlikleri tartışmalıdır $(18,19)$. OHKHN uygulanan hastalarla ilgili daha fazla çalışmaya ihtiyaç vardır. HCT-CI skoruyla genel sağkalım arasındaki ilişkiyi inceleyen çalışmaların metaanalizi ve çalışmamıza ait sonuçlar Tablo-6'da verilmiştir.

Sonuç olarak komorbidite indekslerindeki parametre sayıları arttıkça sağkalımı öngörmedeki duyarlılıkları artmaktadır. Yapılan metaanalizlerde komorbidite indeksleri kullanılarak genel sağkalım ve progresyonsuz sağkalım öngörülebilmektedir. Komorbidite indekslerinin HKHN öncesi rutin kullanma girmesiyle birlikte bu konuyla ilgili tecrübelerimiz artacaktır.

Tablo 6. HCT-CI skoru ile yapılan önceki çalışmaların analizi

\begin{tabular}{|c|c|c|c|c|c|c|c|}
\hline \multirow[t]{2}{*}{$\begin{array}{l}\text { Çalışma } \\
\text { (Kaynak) }\end{array}$} & \multirow[t]{2}{*}{ Yll } & \multirow[t]{2}{*}{$\begin{array}{l}\text { Hasta } \\
\text { sayısı }\end{array}$} & \multirow[t]{2}{*}{ Tanı } & \multicolumn{3}{|c|}{$\begin{array}{l}2 \text { yıllık toplam sağkalım HCT- } \\
\text { CI skoruna göre }(\%)\end{array}$} & \multirow[t]{2}{*}{ p değeri } \\
\hline & & & & Düşük & Orta & Yüksek & \\
\hline Sorror ve ark (7) & 2005 & 364 & AML, KML, MDS & 71 & 60 & 34 & 0.001 \\
\hline Sorror ve ark (15) & 2007 & 244 & AML & 80 & 48 & 33 & $<0.001$ \\
\hline Sorror ve ark (20) & 2007 & 577 & AML, MDS & 64 & & 35 & $<0.001$ \\
\hline Farina ve ark (23) & 2009 & 203 & NHL, MM & 87 & 51 & 49 & $<0.001$ \\
\hline Defor ve ark (24) & 2009 & 444 & AML, NHL, ALL & 62 & 58 & 50 & 0.08 \\
\hline Terwey ve ark (25) & 2010 & 151 & ALL & 58 & 50 & 46 & 0.2 \\
\hline Kataoka ve ark (26) & 2010 & 187 & AML, ALL, KML & 70 & 60 & 39 & $<0.01$ \\
\hline Barba ve ark (10) & 2010 & 194 & AML, MDS, NHL & 54 & 59 & 49 & 0.43 \\
\hline
\end{tabular}




\begin{tabular}{|c|c|c|c|c|c|c|c|}
\hline Kleber ve ark (18) & 2011 & 127 & MM (OKHN) & 61 & & 38 & $<0.002$ \\
\hline $\begin{array}{l}\text { Birninger ve ark } \\
\text { (17) }\end{array}$ & 2011 & 340 & AML & 29 & 40 & 44 & 0.7 \\
\hline $\begin{array}{l}\text { Raimondi ve ark } \\
\text { (30) }\end{array}$ & 2012 & 1937 & AML, ALL, KLL & $*$ & & & $<0.0001$ \\
\hline Nakaya ve ark (31) & 2014 & 243 & AML, ALL, MDS & * & & & 0.44 \\
\hline Saad ve ark (19) & 2014 & 1156 & MM (OKHN) & 83 & & 79 & 0.04 \\
\hline Mevcut çalışma & 2016 & 110 & MM,NHL (OKHN) & 67 & 64 & 63 & 0.897 \\
\hline
\end{tabular}

HCT-CI: Hematopoietic Cell Transplantation Comorbidity İndex, AML: Akut myeloid lösemi, ALL: Akut lenfoid lösemi, MDS: Miyelodisplastik sendrom, MM: Multipl myelom, OHKHN: Otolog hematopoetik kök hücre nakli, AHKHN: Allojenik hematopoetik kök hücre nakli NHL: Non Hodgkin Lenfoma HL: Hodgkin Lenfoma

\section{KAYNAKLAR}

1. Gluckman E, Rocha V, Boyer-Chammard A, et al. Outcome of cord-blood transplantation from related and unrelated donors. $N$ Engl $J$ Med 1997;337:373-81.

2. Gluckman E, Gratwohl A, Apperley J. Hematopoietic stem cell transplantation for primary amyloidosis in adult. The EBMT Handbook 2008;424-30.

3. Graze PR, Gale RP. Autotransplantation for leukemia and solid tumors. Transplant Proc. 1978;10:177-84.

4. Gürman G, Kahveci G, Akan HI, et al. Allogeneic Peripheral Blood Stem Cell Transplantation as A Second Transplant For Severe Aplastic Anemia. Bone Marrow Transplant 1995;15:4850-6.

5. Parimon T, Au DH, Martin PJ, Chien JW. A risk score for mortality after allogeneic hematopoietic cell transplantation. Annals of Internal Medicine, 2006;144:407-14.

6. Sorror ML. Comorbidities and hematopoetic cell transplantation outcomes ASH Education Book 2010;1:237-47.

7. Sorror ML, Maris MB, Storb $\mathrm{R}$, et al Hematopoietic cell transplantation (HCT)-specific comorbidity index: a new tool for risk assessment before allogeneic HCT. Blood 2005; 106:2912-9.

8. Marks DI, Cullis JO, Ward KN, et al. Allogeneic bone marrow transplantation for chronic myeloid leukemia using siblings and volunteer unrelated donors. A comparison in complication in the first 2 years. Ann Intern Med 1993;119:204-14.

9. Sorror ML, Storb R, Sandmaier BM, et al. Comorbidity-age index: a clinical measure of biological age prior to allogeneic hematopoietic cell transplantation. J Clin Oncol. 2014;32:324956.

10. Barba P, Piñana JL, Martino R, et al. Comparison of two pretransplant predictive models and a flexible HCT-CI using different cut points to determine low-, intermediate-, and high- risk groups: the flexible HCT-CI is the best predictor of NRM and OS in a population of patients undergoing allo-RIC. Biol Blood Marrow Transplant 2010;16:413-20.

11. Frenkel WJ, Jongerius EJ, Mandjes-van Uitert MJ, van Munster BC, de Rooij SE. Validation of the
Charlson Comorbidity Index in acutely hospitalized elderly adults: a prospective cohort study. J Am Geriatr Soc 2014;62:342-6.

12. Syrjala KL, Langer SL, Abrams JR, Storer BE, Martin PJ. Late effects of hematopoietic cell transplantation among 10-year adult survivors compared with case-matched controls. J Clin Oncol 2005;23:6596-606.

13. Socié G, Salooja N, Cohen A, et al. Nonmalignant late effects after allogeneic stem cell transplantation. Blood 2003;101:3373-85.

14. Bhatia S, Ramsay NK, Steinbuch M, et al. Malignant neoplasms following bone marrow transplantation. Blood 1996;87:3633-9.

15. Sorror ML, Giralt S, Sandmaier BM, et al. Hematopoietic Cell Transplantation Specific Comorbidity Index As An Outcome Predictor for Patients With Acute Myeloid Leukemia in First Remission: Combined FHCRC and MCACC Experiences. Blood 2007;110:4606-13.

16. Charlson ME, Pompei P, Ales, KL, MacKenzie CR. A New method of classifying prognostic comorbidity in longitudinal studies: Development and validation. Journal of Chronic Diseases 1987;40: 373-83.

17. Birninger N, Bornhauser M, Schaich M, et al. The hematopoietic cell transplantation comorbidity index fails to predict outcomes in high risk AML patients undergoing allogeneic transplantation investigation of potential limitations of the index. Biol of Blood and Marrow Transplantation 2011;17:1822-32.

18. Kleber $M$, Ihorst $G$, Terhorst $M$, et al. Comorbidity as a prognostic variable in multiple myeloma: comparative evaluationof common comorbidity scores and use of a novel MMcomorbidity score. Blood Cancer Journal 2011;1:35-8.

19. Saad A, Mahindra A, Zhang MJ, et al. Hematopoietic Cell Transplant Comorbidity Index Is Predictive of Survival after Autologous Hematopoietic Cell Transplantation in Multiple Myeloma. Biology of Blood and Marrow Transplantation 2014;20:402-8.

20. Sorror ML, Sandmaier BM, Storer BE, et al. Comorbidity and disease status-based risk 
stratification of outcomes among patients with acute myeloid leukemia or myelodysplasia receiving allogeneic hematopoietic cell transplantation. J Clin Oncol 2007;25:4246-54.

21. Majhail NS, Brunstein CG, McAvoy S, et al. Does the Hematopoietic Cell Transplantation Specific Comorbidity Index Predict Transplant Outcomes? A Validation Study in a Large Cohort of Umbilical Cord Blood and Matched Related Donor Transplants. Biology of blood and marrow transplantation. 2008;9:985-92.

22. Guilfoyle R, Demers A, Bredeson C, et al. Performance status, but not the Hematopoietic Cell Transplantation Comorbidity Index(HCT-CI), predicts mortality at a Canadian transplant center. Bone Marrow Transplantation 2009;43:133-9.

23. Farina L, Bruno B, Patriarca F, et al. The hematopoietic cell transplantation comorbidity index (HCT-CI) predicts clinical outcomes in lymphoma and myeloma patients after reducedintensity or non-myeloablative allogeneic stem cell transplantation. Leukemia 2009;23:1131-38

24. DeFor TE, Majhail NS, Weisdorf DJ, Brunstein CG. A modified comorbidity index for hematopoietic cell transplantation. Bone Marrow Transplantation 2010;45:933-8.

25. Terwey TH, Hemmati PG, Martus P, et al. A Modified EBMT Risk Score And The Hematopoietic Cell Transplantation-Specific Comorbidity Index For Pre-Transplant Risk Assessment In Adult Acute Lymphoblastic Leukemia. Haematologica 2010;95: 810-8.

26. Kataoka K, Nannya Y, Ueda K, et al. Differential prognostic impact of pretransplant comorbidity on transplant outcomes by disease status and time from transplant: a single Japanese transplant centre study. Bone Marrow Transplantation 2010;45:513-20.

27. Castagna L, Fürst $S$, Marchetti $N$, et al. Retrospective analysis of common scoring systems and outcome in patients older than 60 years treated with reduced-intencity conditioning regimen and alloSCT. Bone Marrow Transplant 2011;46:1000-5.

28. Patel $P$, Sweiss $K$, Nimmagadda $S$, et al. Comorbidity index does not predict outcome in allogeneic myeloablative transplants conditioned with fludarabine/i.v. busulfan (FluBu4). Bone Marrow Transplantation 2011;46:1326-30.

29. Smith A,Majhail NS, MacMillan ML, et al. Hematopoietic cell transplantation comorbidity index predicts transplant outcomes in pediatric patients. Blood 2011;117:2728-34.

30. Raimondi R, Tosetto A, Oneto R, et al. Validation of the Hematopoietic Cell TransplantationSpecific Comorbidity Index: a prospective, multicenter GITMO Study. Blood 2012;120:132733.

31. Nakaya A, Mori $\mathrm{T}$, Tanaka $\mathrm{M}$, et al. Does the Hematopoietic Cell Transplantation Specific Comorbidity Index (HCT-CI) Predict Transplantation Outcomes? A Prospective Multicenter Validation Study of the Kanto Study Group for Cell Therapy. Biology of blood and marrow transplantation. 2014;10:1553-59.

๑Copyright 2021 by Osmangazi Tıp Dergisi - Available online at tip.ogu.edu.tr @Telif Hakkı 2021 ESOGÜ Tıp Fakültesi - Makale metnine dergipark.org.tr/otd web sayfasından ulaşılabilir. 